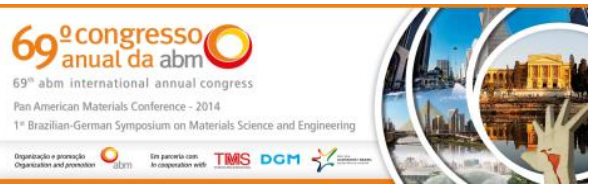

Tema: Gestão de Manutenção

\title{
MELHORIA NA GESTÃO DOS SERVIÇOS DE INSPEÇÃO DE EQUIPAMENTOS NA ARCELORMITTAL TUBARÃ̃O*
}

Severino Albani Junior ${ }^{1}$

\section{Resumo}

Descreve as atividades envolvidas no processo de inspeção e caldeiras de vasos de pressão instalados na usina ArcelorMittal Tubarão, localizada em Vitória - ES. Mostra que esses equipamentos possuem critérios rigorosos não somente para inspeção, mas também de fabricação e operação que necessitam obedecer a códigos de projetos e normas técnicas nacionais e internacionais com objetivo de garantir o funcionamento seguro. Aplica como ferramenta principal no suporte da gestão das atividades um sistema informatizado de manutenção, utilizado em toda usina. Utiliza como pilar na gestão das atividades de inspeção conceitos e ferramentas de planejamento, programação e controle e mostra a complexidade de fazer o controle dessas inspeções numa usina do porte dessa Siderúrgica, que possui uma planta industrial enorme tanto no tamanho, quanto no número de equipamentos e processos existentes. Destaca um grande avanço nos resultados obtidos na gestão das atividades de inspeção dos vasos de pressão e caldeira da ArcelorMittal Tubarão.

Palavras-chave: Inspeção; Manutenção; Vaso de pressão; Caldeira.

\section{MANAGEMENT IMPROVEMENT OF INSPECTION SERVICES IN EQUIPMENT AT ARCELORMITTAL TUBARÃO}

\section{Abstract}

Describes activities regarding inspection process of boilers and pressure vessels installed in the ArcelorMittal Tubarão, in Vitória - ES. These equipment not only have strict criteria for inspection, but also manufacturing and operations that need to obey the code of projects, national and international technical standards in order to ensure operation safe equipment. Applies as the main tool in the management of support activities a computerized maintenance system, used throughout the plant. Use as a pillar in inspection management the concepts of planning, programming and control and shows the complexity to control these inspection in Steel plant, which has a huge industrial plant both in size and in the number of equipment and processes. Highlights a huge advance in the inspection management of pressure vessels and boiler at ArcelorMittal Tubarão.

Keywords: Inspection; Maintenance; Pressure vessel; Boiler.

1 Engenheiro Mecânico, Especialista em Engenharia de Manutenção e Gestão de Projeto, Engenheiro especialista em Manutenção e Gestão de Ativos, Gerência de Tecnologia de Manutenção, ArcelorMittal Tubarão, Vitória, ES, Brasil.

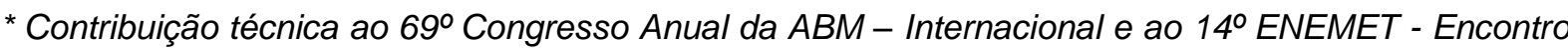
Nacional de Estudantes de Engenharia Metalúrgica, de Materiais e de Minas, 21 a 25 de julho de 2014, São Paulo, SP, Brasil.
} 


\section{INTRODUÇÃO}

Nos últimos anos o mercado tem aumentado as exigências para que as empresas atendam aos requisitos técnicos, tenham melhor qualidade da informação, façam a entrega dos produtos nos prazos estabelecidos, fornecendo um produto de qualidade que atendam suas expectativas. Além disso, as empresas são exigidas cada vez mais para que tenham responsabilidade social, ambiental e que possibilitem que todos seus empregados possam realizar as atividades com toda segurança necessária.

Existem legislações, Normas Técnicas nacionais e internacionais que estabelecem parâmetros de trabalho, limites de exposição e outros fatores que precisam ser controlados para que as atividades sejam executadas com segurança e que os equipamentos operem sem causar acidentes. Acidentes que em muitos casos, possuem causas já conhecidas podendo ser evitados, tais como falhas mecânicas, erros operacionais, erros sucessivos que acumulados causam uma catástrofe.

Dentre os equipamentos industriais que causam acidentes pode se destacar os vasos de pressão e caldeiras que ao longo da história apresentam números representativos como os apresentados na Tabela 1.

Tabela 1: Acidentes com caldeiras e vasos de pressão no mundo [1]

\begin{tabular}{clllll}
\hline Ano & \multicolumn{1}{c}{ País } & \multicolumn{1}{c}{ Local } & Empresa & Mortos & \multicolumn{1}{c}{ Feridos } \\
\hline 1905 & EUA & Brokcton & F. Sapatos & 58 & 117 \\
1947 & EUA & Texas & Porto & 552 & Desconhecido \\
1966 & França & Feyzin & Refinaria & 18 & 80 \\
1972 & Brasil & Duque de Caxias & Refinaria & 37 & Desconhecido \\
1976 & Itália & Sevezo & Química & 500 & 10000 \\
1984 & Índia & Bhopal & Química & 2500 & 20000 \\
1984 & México & Cid. do México & Parq. GLP & 550 & 4200 \\
1984 & Brasil & Cubatão & Duto & 508 & Desconhecido \\
1986 & Rússia & Chernobyl & Nuclear & Desconhecido & 84000 \\
1989 & Rússia & Slbéria & Duto/Trens & 216 & Desconhecido \\
1992 & México & Guadalajara & Duto & 190 & Desconhecido \\
\hline
\end{tabular}

A fim de minimizar ocorrências como essas foram desenvolvidos códigos de projetos de caldeiras e vasos de pressão. Esses códigos estabelecem critérios de projeto para fabricação. No caso do Brasil, além de critérios técnicos também foi regulamentado critérios legais, através da Norma Regulamentadora no 13 (NR-13), Essa Norma estabelece critérios de classificação, instalação, operação, manutenção e principalmente de inspeções desses tipos de equipamentos.

Dessa forma, todas as empresas que possuem vasos de pressão e caldeiras instaladas em suas unidades industriais precisam atender aos requisitos desta Norma. Não diferente, a ArcelorMittal Tubarão (AMT) precisa manter práticas adequadas de controle de possíveis fontes de acidente e atender a todos os requisitos exigidos.

Esse trabalho abordará as atividades, envolvidos, as ferramentas e procedimentos utilizados para que todas as inspeções sejam realizadas nos vasos de pressão e caldeiras eficazmente.

Para isso é necessário um trabalho integrado de Planejamento, Programação e Controle (PPC) que envolve todos os responsáveis pelas atividades a fim de garantir

\footnotetext{
* Contribuição técnica ao 69ำ Congresso Anual da ABM - Internacional e ao 14ํㅡㄹ ENEMET - Encontro Nacional de Estudantes de Engenharia Metalúrgica, de Materiais e de Minas, 21 a 25 de julho de 2014, São Paulo, SP, Brasil.
} 


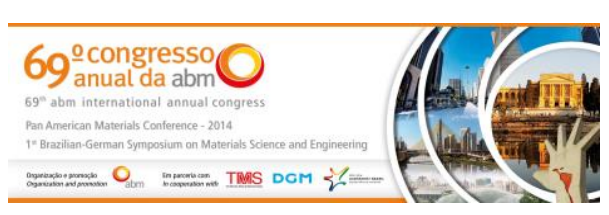

a efetiva execução das inspeções, além de garantir a geração do histórico das atividades executadas, podendo assim controlar melhor os equipamentos.

\section{A ARCELOR MITTAL TUBARÃO}

A ArcelorMittal Tubarão é considerada uma siderúrgica integrada que consiste em adquirir as matérias primas no estado bruto, executar todas as fases do processo industrial e vender os produtos acabados. Necessitando para isso de vários processos distintos dentro do fluxo operacional [2].

\subsection{Gestão da Manutenção}

A manutenção da ArcelorMittal Tubarão tem função estratégica com objetivo de assegura a confiabilidade operacional mediante a maximização da disponibilidade e da vida útil dos ativos. Esse processo está fundamentado na gestão pró-ativa, confiabilidade de ativos, gerenciamento e liderança. Todos fortemente apoiados pelas Engenharias e Tecnologia de Manutenção. A manutenção na usina é realizada no modelo Híbrido com atividades centralizadas, outras descentralizadas, com serviços de apoio e buscando a melhoria contínua utilizando as melhores práticas.

\section{CALDEIRAS E VASOS DE PRESSÃO}

No Brasil existe a Norma Regulamentadora $n-13$ que estabelece as responsabilidades e parâmetros relativos à instalação, operação e manutenção de caldeiras e vasos de pressão. Também define critérios para categorização de caldeiras e vasos de pressão que levam em consideração as características de técnicas e operacionais (pressão, volume, fluido). As Caldeiras possuem Categorias A, B e C e os Vasos de Pressão possuem Categorias I, II, III, IV e V.

\subsection{Inspeções em Caldeiras e Vasos de Pressão}

As caldeiras devem passar por inspeção de segurança inicial, periódica e extraordinária, conforme prazos definidos na Tabela 2 [3].

Tabela 2. Prazos de execução de Inspeções de Segurança

\begin{tabular}{|l|l|l|}
\hline INSPEÇÃO & \multicolumn{1}{|c|}{ CATEGORIA } & \multicolumn{1}{c|}{ QUANDO? } \\
\hline Inicial & A, B e C & Antes de entrar em operação \\
\hline \multirow{4}{*}{ Periódica } & $\begin{array}{l}\text { A, B, C e recuperação } \\
\text { de álcalis }\end{array}$ & 12 meses \\
\cline { 2 - 3 } & "A" & $\begin{array}{l}24 \text { meses (desde que testadas as pressões de } \\
\text { abertura das válvulas de segurança) }\end{array}$ \\
\cline { 2 - 3 } & Caldeiras especiais & 40 meses \\
\hline Extraordinária & Todas & $\begin{array}{l}\text { Caldeiras danificadas, reparadas, após 6 meses } \\
\text { de inatividade ou mudança de local }\end{array}$ \\
\hline
\end{tabular}

Os Vasos de Pressão devem passar por inspeção de segurança inicial, periódica e extraordinária. Os prazos são definidos, pela NR-13, no Tabela 3 para empresas sem Serviço Próprio de Inspeção de Equipamentos (SPIE)

\footnotetext{
* Contribuição técnica ao $69^{\circ}$ Congresso Anual da ABM - Internacional e ao 14ํㅡㄹ ENEMET - Encontro Nacional de Estudantes de Engenharia Metalúrgica, de Materiais e de Minas, 21 a 25 de julho de 2014, São Paulo, SP, Brasil.
} 
Tabela 3. Prazos de inspeção para empresas sem SPIE

\begin{tabular}{|c|c|c|c|}
\hline CATEGORIA & EXAME EXTERNO & EXAME INTERNO & $\begin{array}{l}\text { TESTE } \\
\text { HIDROSTÁTICO }\end{array}$ \\
\hline I & 1 ANO & 3 ANOS & 6 ANOS \\
\hline II & 2 ANOS & 4 ANOS & 8 ANOS \\
\hline III & 3 ANOS & 6 ANOS & 12 ANOS \\
\hline IV & 4 ANOS & 8 ANOS & 16 ANOS \\
\hline$V$ & 5 ANOS & 10 ANOS & 20 ANOS \\
\hline
\end{tabular}

\section{UTILIZAÇÃO DO SISTEMA DE GESTÃO}

O sistema de gestão da manutenção é composto pelos padrões técnicos da manutenção e o sistema de manutenção denominado de sistema informatizado de manutenção de área (SISMANA), sendo utilizado pela área de manutenção, operação, áreas de apoio e empresa contratadas. Conforme mostra a Figura 1, ele estruturado em módulos [4].

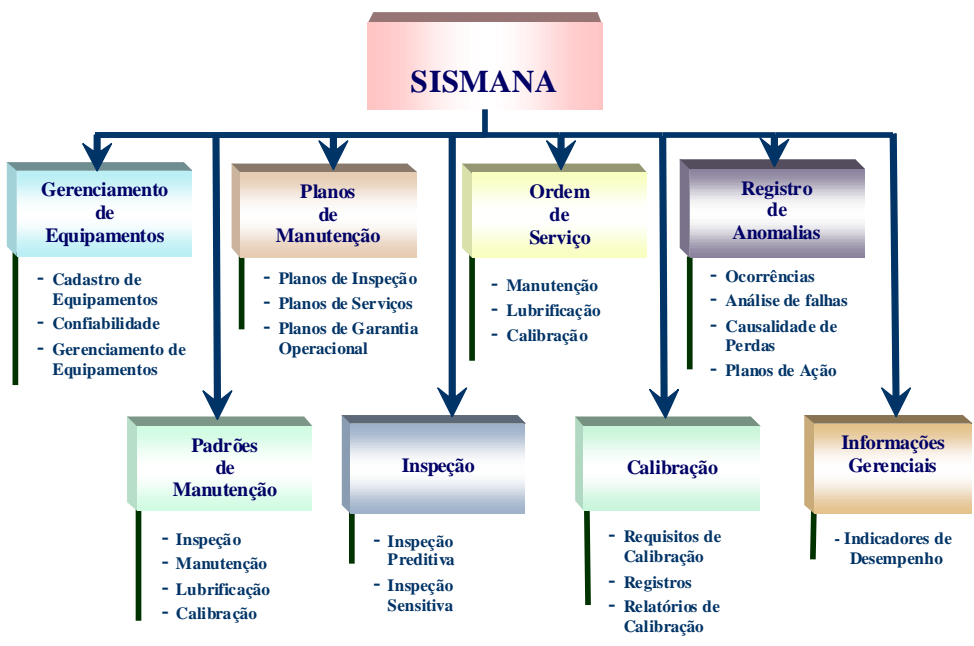

Figura 1. Diagrama do Sistema Informatizado de Manutenção [2].

\section{GESTÃO DAS INSPEÇÕES DE VASOS DE PRESSÃO E CALDEIRAS}

Esse trabalho aborda a gestão das inspeções realizadas em vasos de pressão e caldeiras com objetivo de detectar anormalidades que possam comprometer a operação segura dos mesmos. Essas inspeções são realizadas através de inspeções visuais, teste hidrostático e através de ensaios não destrutíveis. Os ensaios não destrutíveis convencionais mais utilizados nas inspeções estão citados na tabela 4.

Tabela 4: Ensaios Não Destrutíveis convencionais

\begin{tabular}{|ll|}
\hline \multicolumn{1}{|c|}{ Tipo de Ensaio } & \multicolumn{1}{c|}{ Objetivo } \\
\hline Ultrassom & Medir de espessura \\
Ultrassom & Identificar de descontinuidades e falha de fabricação \\
Líquido penetrante & Identificar trincas superfíciais \\
Partícula Magnética & Identificar trincas subsuperfíciais \\
\hline
\end{tabular}

\footnotetext{
* Contribuição técnica ao 69ำ Congresso Anual da ABM - Internacional e ao 14ํㅡㄹ ENEMET - Encontro Nacional de Estudantes de Engenharia Metalúrgica, de Materiais e de Minas, 21 a 25 de julho de 2014, São Paulo, SP, Brasil.
} 


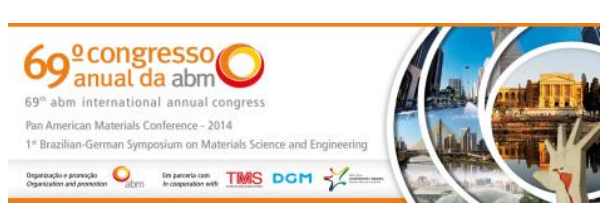

Também existem diversas outras técnicas que são aplicadas conforme necessidade e avaliação da equipe técnica. Para realizar as inspeções é necessária de diversos serviços complementares tais como a retirada de isolamento térmico, montagem de andaimes, retirada de óleo de equipamentos hidráulicos, sobressalentes, abertura e fechamento de boca de visita, acesso por alpinismo, remover feixes tubulares, etc. Para uma correta execução é necessário de um planejamento, programação e controle muito bem ajustado para que as interferências e consequentemente, atrasos e cancelamentos de serviços sejam minimizados.

\subsection{Estratégia da Manutenção Praticada na Manutenção}

O modelo de gestão hibrido adotado pela ArcelorMittal Tubarão consiste na execução das inspeções por uma empresa contratada, gerenciado pela equipe própria. Esse modelo de gestão evoluiu e está caracterizado em duas etapas.

\subsubsection{Primeira etapa}

A empresa contratada era responsável pelas inspeções e a companhia pela disponibilização dos serviços complementares. Nessa fase ficou clara a necessidade de alterar o modelo de gestão, ou ao menos, agregar mais atividades à própria empresa de inspeção para que fosse possível aumentar a eficácia das inspeções, já que as reclamações de clientes eram muitas, assim como os serviços cancelados. Foi desenvolvido um trabalho multidisciplinar que identificou problemas e gargalos do processo existente e propôs ações para minimizá-los. Todo esse trabalho subsidiou as mudanças na gestão das atividades de inspeção, culminando na segunda etapa que será descrita a frente.

\subsubsection{Segunda etapa}

Nessa etapa houve um grande avanço na gestão das atividades de inspeção principalmente na programação das atividades. Além de avaliar o equipamento, as inspeções são requisitos de Norma e visando melhor cumprimento, foi definido de forma macro os responsáveis desses requisitos dentro da usina. Segue na Figura 2 a divisão de responsabilidade.

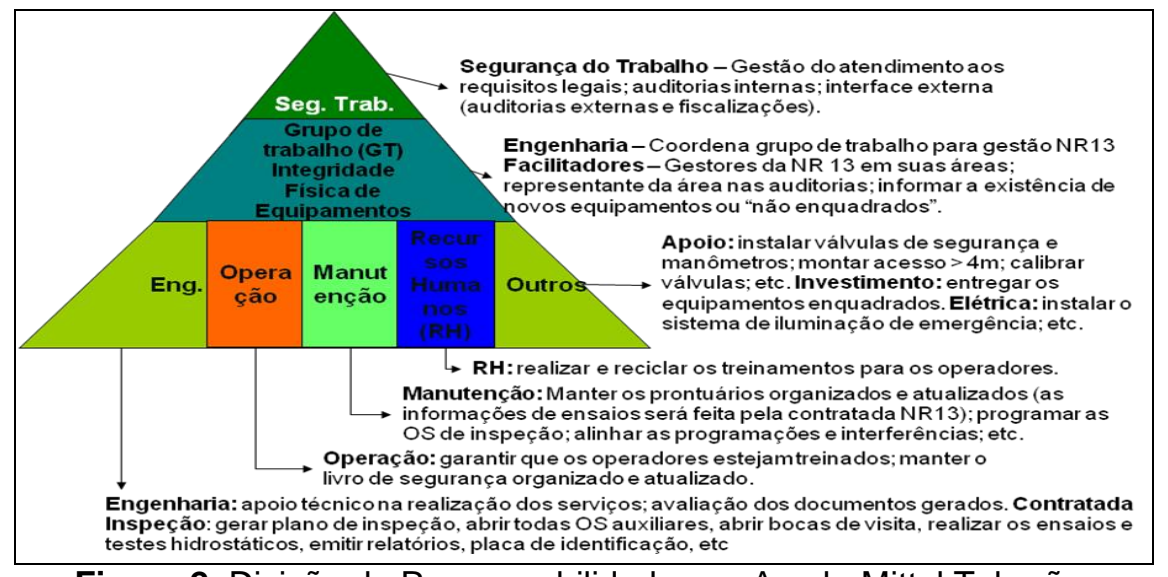

Figura 2. Divisão de Responsabilidades na ArcelorMittal Tubarão.

Também foi elaborado um padrão empresarial destacando as responsabilidades, definido os responsáveis por todos os serviços complementares que suportam a realização das inspeções [5].

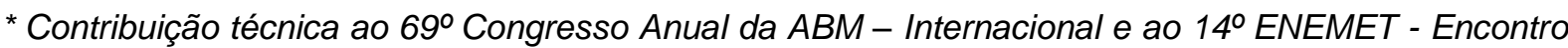
Nacional de Estudantes de Engenharia Metalúrgica, de Materiais e de Minas, 21 a 25 de julho de 2014, São Paulo, SP, Brasil.
} 


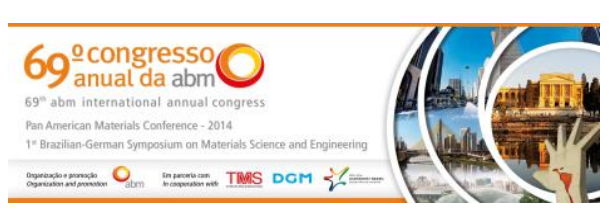

A elaboração do plano de serviços é uma das atividades mais importante em todo processo, pois define os recursos necessários, quem os fornecerá e executará cada atividade, onde serão utilizados, quanto tempo precisam estar disponíveis e qual será a periodicidade da inspeção.

Todo levantamento dessas informações é feito em campo e anexado no SISMANA, onde é criado um plano de serviço. Todo processo de aprovação do plano no sistema pode ser observado esquematicamente na Figura 3.

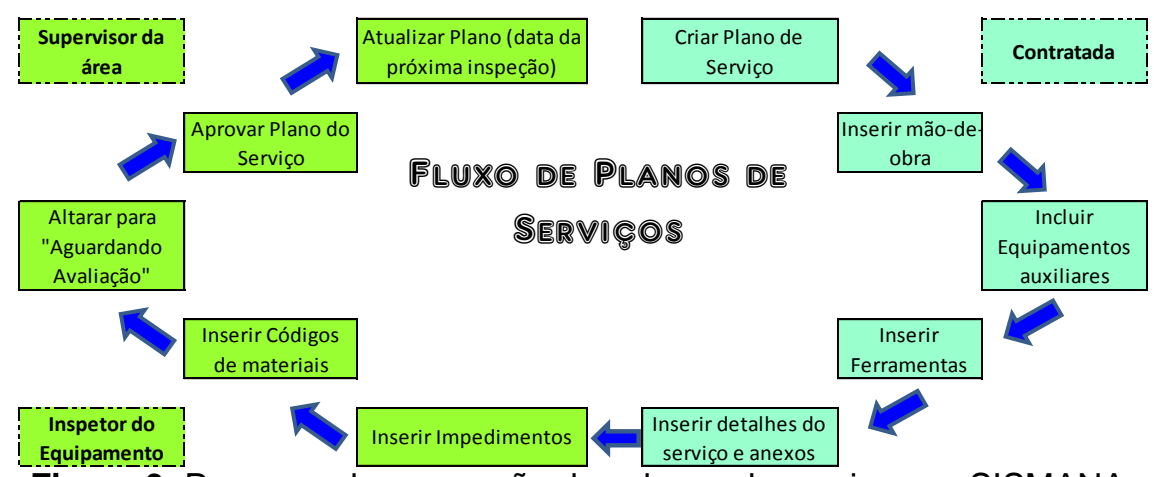

Figura 3. Processo de aprovação dos planos de serviços no SISMANA.

\section{CRITÉRIOS DE AVALIAÇÃO E PERIODICIDADE APLICÁVEIS NA INSPEÇÃO}

A inspeção dos vasos de pressão em atendimento a NR-13 devem ocorrer de 3 maneiras: exame externo, exame interno e teste hidrostático. A inspeção externa consiste numa análise holística do equipamento, avaliando os requisitos no entorno dele, a documentação existente além das medições anteriores. A realização do exame interno depende da existência de acesso para uma pessoa que avaliará possíveis mecanismos de danos existentes que possam comprometer a integridade do equipamento. O teste hidrostático consiste na elevação da pressão do equipamento acima da pressão máxima de trabalho admissível conforme código de projeto aplicável.

Feita essas inspeções, é gerado o relatório que deverá ser assinado e guardado junto ao prontuário do equipamento na área, atualizando a planilha de gestão e livro de registro. Essa planilha de gestão é a ferramenta utilizada na usina para controlar todas as informações dos equipamentos. O atendimento aos requisitos é avaliado em auditorias, considerando todas as variáveis do processo, permitindo uma melhoria contínua.

\subsection{Prazo de Inspeção dos Requisitos}

A Norma define a frequência dos exames para os vasos de pressão e para as caldeiras e estabelece os requisitos a serem avaliados. Esses requisitos foram estratificados em 2 grupos:

1. Requisitos de Inspeção (exame externo, exame interno e teste hidrostático);

2. Requisitos de Documentação (todos os outros requisitos).

Uma das análise foi sobre os requisitos de documentação que engloba: placa instalada e com todas as informações necessárias, faixa instalada e todas as informações necessárias, dispositivo de segurança e manômetro calibrados, iluminação de emergência instalada e funcionando, prontuários com a

\footnotetext{
* Contribuição técnica ao $69^{\circ}$ Congresso Anual da ABM - Internacional e ao 14ํㅡㄹ ENEMET - Encontro Nacional de Estudantes de Engenharia Metalúrgica, de Materiais e de Minas, 21 a 25 de julho de 2014, São Paulo, SP, Brasil.
} 
documentação necessária, livros de registro disponíveis e preenchidos corretamente.

Em auditorias internas foi identificado que as informações da planilha de gestão não estavam confiáveis. Então foi realizado um trabalho em duas frentes por equipe distintas.

A primeira teve a responsabilidade de avaliar as informações existentes dos equipamentos (em prontuários e na área), confrontando-as com a planilha de gestão e atualizando-as de maneira adequada. Só depois as inspeções seriam realizadas.

A outra equipe teve os serviços definido conforme os seguintes critérios:

a) Iniciar pelos vasos de categorias I, II e III e depois os de categorias IV e V;

b) Avaliar a eficácias dos requisitos de documentação;

c) Todas as informações de cada equipamento deveriam ser avaliadas por uma única pessoa, isto é, se uma pessoa iniciasse a avaliação, ela deveria avalialo até o final para não ocorrer dúvida ou perda de informação;

d) Definir um fluxo para atualização das informações na planilha de gestão;

e) Todos os desvios encontrados deveriam ser eliminados de imediato.

Nesse processo de atualização, foram identificados pontos vulneráveis no controle de informações da planilha de gestão que merecem destaque:

a) a planilha de gestão controla as informações dos requisitos de documentação com base na ultima inspeção externa. Isso pode não retratar a realidade, já que esses equipamentos sofrem intervenções (Ex. manutenção) que ocasionam a perda das placas e faixas de identificação, por exemplo;

b) não havia processo sistêmico para as calibrações dos dispositivos de segurança e manômetros;

c) perda de informação e documentos.

Com as informações atualizadas e desvios mapeados, foi possível avançar no trabalho permitindo definir critérios tais como responsável, prazos e os requisitos a serem acompanhados fora dos períodos de inspeção externa.

\subsubsection{Prazo de identificação}

Com essas constatações foi criada uma rotina de acompanhamento com periodicidade menor que os exames externos. Essa avaliação foi realizada pelos inspetores próprios da usina, tendo suporte ao SISMANA. Desvios identificados eram atualizados na planilha de gestão.

A calibração dos dispositivos de segurança deveria ter duas saídas: o certificado de calibração anexado ao prontuário e comunicação da calibração a área cliente para atualizar a planilha de gestão.

\section{DEFINIÇÃO DAS MELHORIAS PROPOSTAS}

\subsection{Controle da Atualização das Informações}

Os desvios de informação estavam causando retrabalho e baixa confiabilidade da informação. A planilha de gestão é a ferramenta utilizada para o controle das informações dos equipamentos, sendo necessário que todas as informações nela contida estejam corretas. Um grupo formado por representantes da Contratada e de da Companhia identificou as principais causas dos desvios de atualização da planilha de gestão:

a) não existia um fluxo de atualização de informação estruturado;

b) não existia um período definido para atualizar a planilha de gestão;

* Contribuição técnica ao $69^{\circ}$ Congresso Anual da ABM - Internacional e ao 14ํㅡㄹ ENEMET - Encontro Nacional de Estudantes de Engenharia Metalúrgica, de Materiais e de Minas, 21 a 25 de julho de 2014, São Paulo, SP, Brasil. 


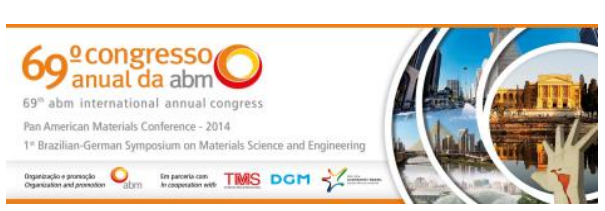

c) muitas pessoas atualizavam aleatoriamente, gerando desvios;

d) não existia limitação de acesso e modificação na planilha de gestão;

e) desvios nas fontes de informação (ordem de serviço e relatórios);

f) não era realizada a verificação das informações atualizadas.

Ações de controle foram tomadas, tais como a elaboração do fluxograma apresentado definido "o que" e "quem" é responsável em cada etapa.

\subsection{Controle dos Registros de Atendimento aos Requisitos}

O total de registros a serem controlados nesse processo de inspeção gira em torno de 20.000 itens. Para isso é necessário um conjunto de ferramentas e procedimentos adequados que permitam que as informações estejam disponíveis e corretas quando necessárias.

Foi criado um controle das recomendações provenientes das inspeções já que elas não estavam sendo tratadas. Segue o modelo de controle na Figura 4.

\begin{tabular}{|c|c|c|c|c|c|c|}
\hline \multicolumn{7}{|c|}{ PLANILHA DE RECOMENDAÇÃO DA INSPEÇÃO } \\
\hline ÁREA & EQUIPAMENTO & $\mathrm{N}^{\circ} \mathrm{RT}$ & RECOMENDAÇÕES & RESP. & DATA & STATUS \\
\hline \multirow[t]{5}{*}{ IDG } & \multirow{5}{*}{$\begin{array}{l}\text { CONDENSADOR DE } \\
\text { VAPOR DA TURBINA }\end{array}$} & \multirow[t]{5}{*}{ RT 55.117} & $\begin{array}{l}\text { Tamponar os tubos com indicações classe } 4 \text { e os tubos } \\
\text { obstruídos. }\end{array}$ & & & \\
\hline & & & Instalar iluminação de emergência & & & \\
\hline & & & Calibrar válvula de segurança & & & \\
\hline & & & Calibrar manômetro & & & \\
\hline & & & $\begin{array}{c}\text { Programar troca dos parafusos da tampa das } \\
\text { câmaras A e B na próxima Darada do equipamento. }\end{array}$ & & & \\
\hline
\end{tabular}

Figura 4. Planilha de Recomendação [2].

A Figura 5 mostra os tipos de recomendações identificadas e o índice de recomendações por área. Isso só foi possível após mapeamento das recomendações.

\begin{tabular}{|l|}
\hline \multicolumn{1}{|c|}{ Recomendações das inspeções } \\
\hline $\begin{array}{l}\text { Anexar certificado de calibração da válvula de } \\
\text { segurança ao prontuário }\end{array}$ \\
\hline $\begin{array}{l}\text { Anexar certificado de calibração do } \\
\text { manômetro ao prontuário }\end{array}$ \\
\hline Calibrar manômetro \\
\hline Calibrar válvula de segurança \\
\hline Elaborar memória de cálculo \\
\hline Eliminar vazamentos existentes \\
\hline Identificar manômetros e válvula de segurança \\
\hline Instalar aterramento \\
\hline Instalar manômetro \\
\hline Instalar válvula de segurança \\
\hline Pintar as regiões corroídas \\
\hline Realizar limpeza do local \\
\hline Recuperar as estruturas de concreto \\
\hline Reparar o suporte das tubulações e do \\
equipamento \\
\hline Tamponar tubos furados ou com vazamentos \\
\hline Trocar parafusos corroídos \\
\hline
\end{tabular}
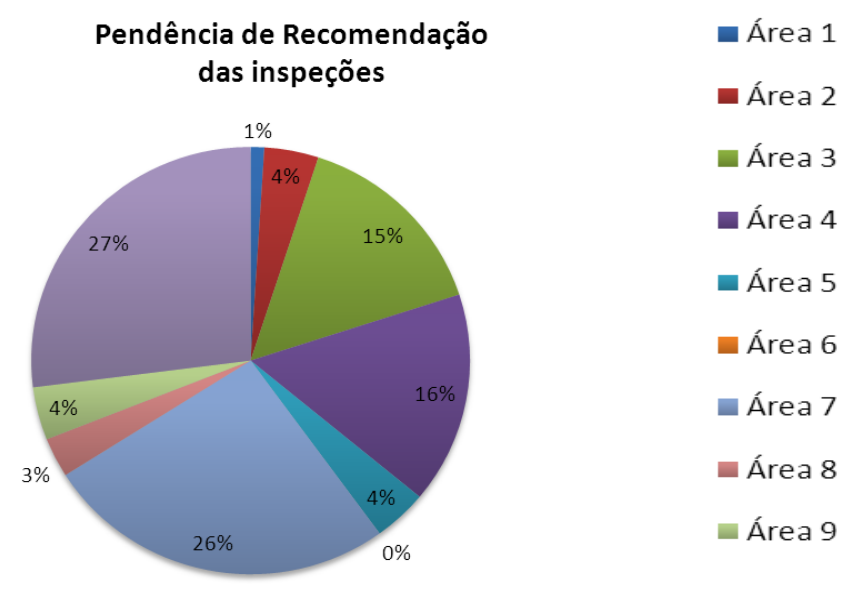

Figura 5. Tipos de Recomendação e Índice por Área cliente [2].

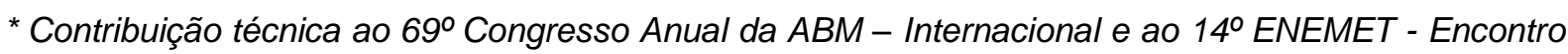
Nacional de Estudantes de Engenharia Metalúrgica, de Materiais e de Minas, 21 a 25 de julho de 2014, São Paulo, SP, Brasil.
} 


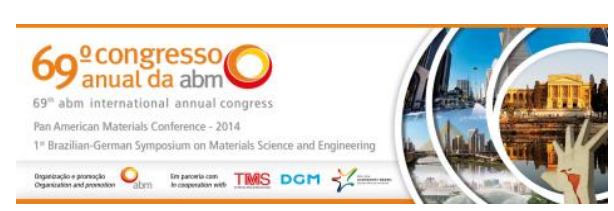

\subsection{Estratificação das Causas de Cancelamento}

O índice de serviços cancelados nesse período estava próximo a 20\%. A Tabela 5 mostra as causas de cancelamentos de 114 ordens de serviços ocorridas em 33 semanas de 2011.

Os cancelamentos geraram um impacto financeiro em torno de $R \$ 200.000,00$. A Figura 6 apresente o percentual por tipo de cancelamentos e mostra que a maior parcela de cancelamento está relacionada ao planejamento e programação.

A Figura 7 mostra a relação entre os tipos de exames que seriam realizados quando o serviço foi cancelado. Os serviços mais cancelados são os Testes Hidrostáticos, seguido dos exames internos pois dependem que o equipamento esteja parado e disponibilizado para o ensaio, aumentando as interferências para a inspeção.

Outra análise considerou os tipos de falhas ocorridas nas áreas clientes (gráfico 3). Foi identificado que a maioria dos cancelamentos ocorreu nas áreas A, B e C, totalizando 75 serviços, que corresponderam a $66 \%$ de todos os cancelamentos do período. Aprofundando mais, dos 75 cancelamentos, 74 estão concentrados em três tipos de falha como mostrado no detalhe da Figura 8 . A conclusão é que $65 \%$ dos tipos de cancelamentos estão concentrados em três tipos de falhas e em três áreas clientes, onde foram concentradas as ações de controle para minimizá-los.

Tabela 5. Principais tipos de cancelamentos

\begin{tabular}{|c|c|}
\hline Tipos dos Cancelamentos & Detalhamento \\
\hline Condição climática & Chuvas torrenciais \\
\hline \multirow{2}{*}{ Falha de manutenção } & Equipamento com vazamento \\
\hline & Válvula dando passagem ou não abriu para drenar \\
\hline \multirow{3}{*}{$\begin{array}{l}\text { Falha ou falta do Recurso de } \\
\text { apoio }\end{array}$} & Efetivo deslocado para atender emergência \\
\hline & Falha na drenagem do equipamento \\
\hline & Faltou efetivo lubrificação e não foi montado andaime \\
\hline \multirow{5}{*}{ Falha PPC Área } & Faltou aprovar planos e impedimento errado \\
\hline & Não alinhado entre PPCs e não forneceram juntas \\
\hline & Não informado código SISMANA \\
\hline & Não programada abertura \\
\hline & Não programou abertura do vaso \\
\hline $\begin{array}{l}\text { Falha PPC Contratada de } \\
\text { Inspeção }\end{array}$ & $\begin{array}{l}\text { Acesso para exame inviável } \\
\text { Água caindo sobre o vaso }\end{array}$ \\
\hline
\end{tabular}

\section{Causa de Cancelamentos}

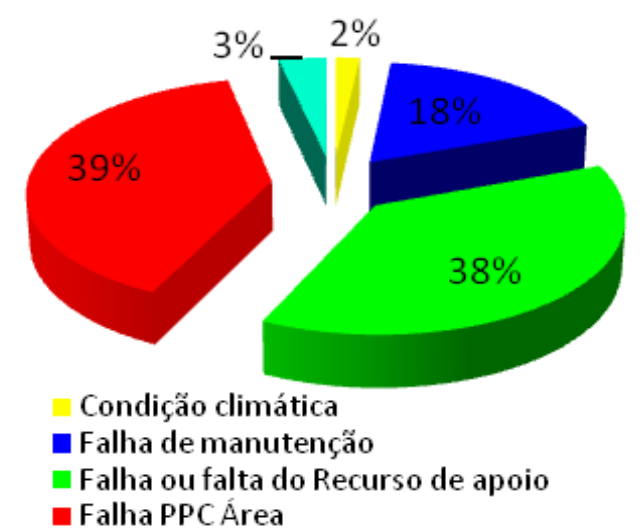

Figura 6. Tipos de cancelamento [2].

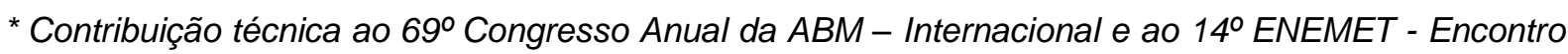
Nacional de Estudantes de Engenharia Metalúrgica, de Materiais e de Minas, 21 a 25 de julho de 2014, São Paulo, SP, Brasil.
} 


\section{Cancelamentos por Tipo de Ensaio}
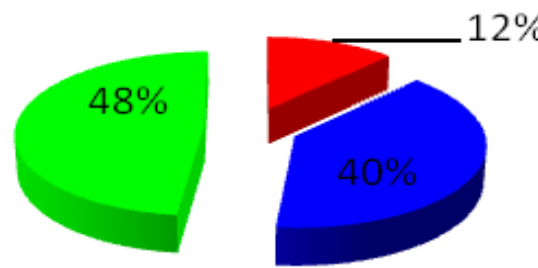

Exame Externo

- Exame Interno

Teste Hidrostático

Figura 7. Cancelamento por Tipo de Ensaio [2]

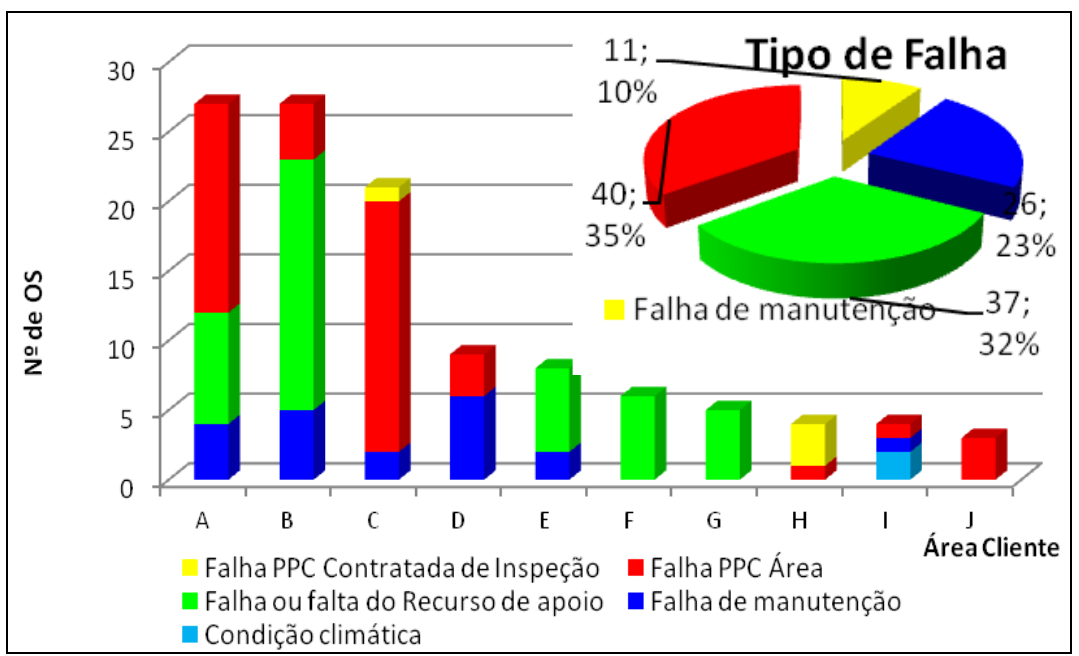

Figura 8. Cancelamento por área cliente [2].

\subsubsection{Metodologia para tratamento das causas dos cancelamentos}

Primeiramente, foram identificados quais itens eram mais relevantes dentre os 74 cancelamentos conforme causas apresentadas na Tabela 6.

Tabela 6. Tipos de cancelamentos nas áreas A, B e C

\begin{tabular}{|c|c|c|c|}
\hline \multirow{2}{*}{ Tipo do Cancelamento } & \multirow{2}{*}{ Detalhamento do Cancelamento } & \multicolumn{2}{|c|}{ Ocorrências } \\
\hline & & Qtd. & $\%$ \\
\hline $\begin{array}{l}\text { Falha ou falta do Recurso de } \\
\text { apoio }\end{array}$ & Faltou efetivo lubrificaç & 30 & $41 \%$ \\
\hline Falha PPC Área & Não programada abertura & 12 & $16 \%$ \\
\hline $\begin{array}{l}\text { Falha ou falta do Recurso de } \\
\text { apoio }\end{array}$ & $\begin{array}{l}\text { Efetivo deslocado para } \\
\text { emergência }\end{array}$ & 8 & $11 \%$ \\
\hline Falha PPC Área & Impedimento errado & 8 & $11 \%$ \\
\hline Falha PPC Área & Não foram fornecidas juntas & 6 & $8 \%$ \\
\hline Falha de manutenção & Válvula dando passagem & 5 & $7 \%$ \\
\hline Falha PPC Área & Faltou aprovar planos & 5 & $7 \%$ \\
\hline Total & & 74 & $100 \%$ \\
\hline
\end{tabular}

\footnotetext{
* Contribuição técnica ao 69 Congresso Anual da ABM - Internacional e ao 14ํㅡㄹ ENEMET - Encontro Nacional de Estudantes de Engenharia Metalúrgica, de Materiais e de Minas, 21 a 25 de julho de 2014, São Paulo, SP, Brasil.
} 
As causas de cancelamentos foram tratadas de acordo com o responsável:

a. tratamento da falha ou falta de recurso de apoio ( 51\%):

- falta de efetivo de lubrificação: o recurso centralizado de lubrificação era disponibilizado pela área de apoio e atendia a usina toda. Ação: não foram programados serviços que dependessem de recursos de lubrificação por 30 dias. Após avaliação ficou definido que a área cliente iria disponibilizar recurso próprio, não dependendo da área de apoio.

- efetivo deslocado para atendimento de emergência: esse item não foi possível ser tratado, visto que emergências não são programáveis. Ainda sim foi analisada a possibilidade de aumento de recursos de apoio para atendimento às inspeções, o que também não foi viável no cenário atual.

b. tratamento de falha do PPC da área ( 42\%): as causas estão diretamente ligadas à rotina de atividades da área de planejamento, programação e controle. Ação: reunião com os PPC das áreas, apresentando as causas dos cancelamentos e o impacto financeiro gerado. Solicitado que a programação de serviços de inspeção seja realizada com pelo menos 4 semanas de antecedência.

c. tratamento de falha de manutenção ( 7\%): É necessário avaliar o funcionamento das válvulas (vazamento interno) antes do dia do ensaio, visto que no dia do teste não é possível executar qualquer reparo e/ou substituição dessas válvulas.

O teste das válvulas deve ser incluído no programa de manutenção da área cliente para que desvios identificados possam ser reparados antes das inspeções. Caso isso não ocorra ou não seja possível, a área cliente deve informar a engenharia, para que a programação do teste não seja executada.

\section{RESULTADOS OBTIDOS}

O Gerenciamento da informação foi uma etapa fundamental no processo de melhoria da gestão das inspeções na usina. Com melhora da comunicação alcançada através de reuniões entre todos os envolvidos no processo foi possível definir um fluxo de atualização e controle integrado da informação gerada.

Os ganhos obtidos com as melhorias implantadas puderam ser identificados em duas auditorias internas e uma externa. Nelas foi avaliado o controle das informações existentes, obtendo resultado satisfatório entre as informações da planilha de gestão e as informações das áreas.

Ainda sim foram identificados alguns desvios de informações técnicas de memória de cálculo e dados operacionais, que ainda não tinha sido tratado, podendo ser fruto de trabalhos futuros.

A Planilha de Recomendação trouxe avanço no controle das recomendações, permitindo atuar junto aos responsáveis e melhorar o nível de enquadramento dos equipamentos. Ela permitiu a todos envolvidos conhecerem as recomendações, permitindo programar as ações necessárias para corrigi-las, sendo um destaque positivo na ultima auditoria.

O nível de cancelamento nas 33 semanas analisadas foi de aproximadamente 3,5 serviços por semana. Depois das ações implementadas, esse índice reduziu para 1,1 , uma redução de $68 \%$. Isso demonstra que as ações adotadas trouxeram 0 ganho esperado.

* Contribuição técnica ao 69 Congresso Anual da ABM - Internacional e ao 14ํㅡㄹ ENEMET - Encontro Nacional de Estudantes de Engenharia Metalúrgica, de Materiais e de Minas, 21 a 25 de julho de 2014, São Paulo, SP, Brasil. 
A adequação do processo de calibração trará como resultados os seguintes benefícios:

a) atender ao requisito de documentação;

b) atender as recomendações de inspeções;

c) atender os requisitos das normas ISO-9001;

d) gerar informação confiável na planilha de gestão;

e) possuir manômetros e válvulas de segurança calibrados;

f) aumentar a segurança de operação das válvulas e vasos de pressão.

O resultado do processo de calibração será a geração dos certificados de calibração e as etiquetas de calibração, que servirá como evidência para mostrar que as os manômetros e válvulas de pressão estarão sendo monitorados e aferidos, atendendo aos requisitos de auditorias.

\section{CONCLUSÃO}

Esse trabalho permitiu melhorar os diferentes processos existentes na gestão de inspeção, mostrando que a comunicação por mais clara que possa parecer para o comunicador nem sempre é entendida pelo ouvinte, necessitando ser melhorada até um nível ideal de entendimento entre as partes.

Mostrou também que ações bem coordenadas proporcionaram a redução do nível de cancelamento e que a utilização de um sistema de manutenção proporciona uma melhoria no controle e qualidade de informação e otimização de recursos no processo de inspeção.

Algumas das melhorias propostas nesse trabalho ainda não puderam ser quantificadas, mas vem mostrando que estão adequadas com o objetivo a ser alcançado que é realizar inspeções com qualidade, dentro do prazo, utilizar técnicas de inspeções avançadas, conhecer as recomendações, otimizar recursos e permitir o controle adequado de todas essas informações entre as partes envolvidas (área cliente, empresa de inspeção, engenharia e parte externa como auditores).

\section{REFERÊNCIAS}

1 Souza LA. Moschini. Curso de Regulamentação de Caldeiras e Vasos de Pressão, NR13. Rio de Janeiro: IBP; 2010.

2 ArcelorMittal Tubarão. [acesso em 20 jul. 2010]. Disponível em: $<$ http://www.arcelormittal.com/br/ tubaraos.

3 Ministério do Trabalho e Emprego. Norma Regulamentadora ํㅜ 13. [acesso em 25 mai. 2013]. Disponível em: <http://www.mte.gov.br/legislacao/normas_regulamentadoras/nr_13>.

4 ArcelorMittal Tubarão. Sistema Informatizado de Manutenção - SISMANA: Manual do Sistema. Serra: ArcelorMittal Tubarão; 2011.

5 ArcelorMittal Tubarão. Padrão Empresarial: PE-SGS-0061 Diretrizes para o Cumprimento da NR13 - Caldeiras e Vasos de Pressão da ArcelorMittal Tubarão. Serra: ArcelorMittal Tubarão; 2011.

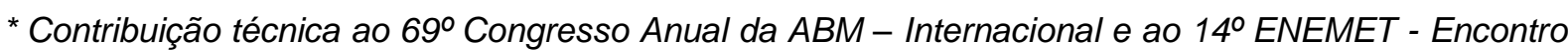
Nacional de Estudantes de Engenharia Metalúrgica, de Materiais e de Minas, 21 a 25 de julho de 2014, São Paulo, SP, Brasil.
} 